GRASAS Y ACEITES 71 (2)

April-June 2020, e350

ISSN-L: 0017-3495

https://doi.org/10.3989/gya.0229191

\title{
Preparation of novel nanoemulsions from omega-3 rich oil
}

\author{
S.F. Hamed and G.A. Abo-Elwafa ${ }^{\circledR}$ \\ Fats and Oils Department, National Research Centre, El-Buhouth St., Dokki, Cairo, Egypt, Postal code 12622 \\ Corresponding author: gada_abo@hotmail.com
}

Submitted: 25 February 2019; Accepted: 02 April 2019; Published online: 19 May 2020

SUMMARY: This work aimed to produce stabilized omega-3-rich oil in a water nanoemulsion using a highpressure homogenizer (HPH). Studies were carried out on the effects of the type of the emulsifier and its concentration, HPH conditions (pressure and number of passes inside the homogenization chamber) as well as continuous phase viscosity on the polydispersity index (PDI) and mean droplet size of the nanoemulsion were carried out. The impact of rosemary extract on the oxidative stability of the emulsion was also monitored. Results showed that small molecular weight emulsifiers gave small droplet size and vice versa. In addition, the results revealed that a parallel decrease in mean droplet diameter was observed with increases in emulsifier concentration, homogenization cycles (passes) and homogenization pressure. Furthermore, when the viscosity of the aqueous phase increased, a slight non-significant and irregular fluctuation in the droplet size was detected. The results demonstrated that rosemary extract enhanced the oxidative stability of this nanoemulsion. Our results could help in formulating stabilized omega-3-enriched nanoemulsions that could be applied in different food stuffs.

KEYWORDS: Emulsifier Concentration; Emulsifier Type; High Pressure Homogenization; Homogenization Conditions; Nanoemulsion

RESUMEN: Preparación de nuevas nanoemulsiones a partir de aceite rico en omega-3. Este trabajo tuvo como objetivo producir nanoemulsiones de aceite rico en omega-3 estabilizado en agua usando un homogeneizador de alta presión (HPH). Estudiando los efectos del tipo de emulsionante y su concentración, se llevaron a cabo las condiciones de HPH (presión y número de pasadas dentro de la cámara de homogeneización), así como la viscosidad de fase continua en el índice de polidispersidad (PDI) y el tamaño medio de gota de la nanoemulsión. También se siguió el impacto de la adición de extracto de romero sobre la estabilidad oxidativa de la emulsión. Los resultados mostraron que los emulsionantes de peso molecular pequeño dieron un tamaño de gota pequeño y viceversa. Los resultados también revelaron que hay una disminución paralela en el diámetro medio de las gotitas con el aumento de la concentración de emulsionante, los ciclos de homogeneización (pases) y la presión de homogeneización. Además, cuando aumentó la viscosidad de la fase acuosa, se observó una ligera fluctuación no significativa e irregular en el tamaño de la gota. Además, los resultados demostraron que el extracto de romero mejoró la estabilidad oxidativa de esta nanoemulsión. Nuestros resultados podrían ayudar a formular nanoemulsiones enriquecidas con omega-3 estabilizadas que podrían aplicarse en diferentes alimentos.

PALABRAS CLAVE: Concentración de emulsionante; Condiciones de homogeneización; Homogeneización a alta presión; Nanoemulsion; Tipo de emulsionante

ORCID ID: Hamed SF https://orcid.org/0000-0001-5086-7110, Abo-Elwafa GA https://orcid.org/0000-0002-2681-6249

Citation/Cómo citar este artículo: Hamed SF, Abo-Elwafa GA. 2020. Preparation of novel nanoemulsions from omega-3 rich oil. Grasas Aceites 71 (2), e350. https://doi.org/10.3989/gya.0229191

Copyright: (C2020 CSIC. This is an open-access article distributed under the terms of the Creative Commons Attribution 4.0 International (CC BY 4.0) License. 


\section{INTRODUCTION}

Nanotechnology has become a leadong technique for industrial innovation (Kabri et al., 2011). Nanoemulsions are gaining attention in many industries (e.g. food, cosmetics and nutraceuticals) as potential vehicles that enhance the bioavailability, absorbitivity and bioactivity of lipophilic nutrients (e.g. fatty acids, phenolic compounds, vitamins, natural pigments and flavors) (Sagalowicz and Leser, 2010; Wang et al, 2009; Guglielmini, 2008; Mao et al., 2009).

Food nanoemulsions are superior emulsions with respect to their properties suchas visual clarity, high stability against gravimetrical separation, and improved absorptivity and the bioavailability of nutraceutical components (Wang et al., 2008; Shafiq et al., 2007). Interest has increased in developing nutraceuticals and fortified foods to fight different diseases (e.g. cancer and obesity).

Nanoemulsions [oil in water $(\mathrm{O} / \mathrm{W})$, or water in oil (W/O)] with small droplet sizes (i.e. nano-scale diameters) are characterized by their translucent or transparent appearance and superior delivery functions that are important for food and pharmaceutical industry sectors to encapsulate lipophilic substances (e.g. lipophilic drugs and omega-3-rich oils) and increase their bioavailability and absorbitivity.

Mcclements and Rao (2011) described high pressure homogenizers as the most common method of producing conventional emulsions with small droplet sizes in the food industry as they are more effective methods in reducing the size of the droplets in pre-existing coarse emulsions than creating emulsions directly from two immiscible liquids.

Docosahexanoic acid (DHA), eicosapentanoic acid (EPA) and $\alpha$-Linolenic acid are important members of the omega- 3 fatty acids. $\alpha$-Linolenic acid is the essential fatty acid and serves as a precursor for longer-chain polyunsaturated fatty acids as the body converts it readily after ingestion to EPA and more slowly to DHA. These important fatty acids are metabolized by body enzymes into anti-inflammatory and anti-proliferative metabolites that have been found to be active in preventing cardiovascular diseases and inflammatory disorders of the skin (Din et al., 2004; Kris-Etherton et al., 2003), minimizing the symptoms associated with rheumatoid arthritis (Fortin, 1995) and enhancing treatment for depression and schizophrenia (Peet and Stokes, 2005).

However, the main problem in the quality of omega-3 PUFA oils lies in their high susceptibility to oxidation during storage or food processing (Comporti, 1993).

Herbs and spices have phytochemicals such as flavonoids, phenolic diterpenes, tannins and phenolic acids, which are sources of many antioxidants. These compounds have antioxidant, antimicrobial and anticancer properties. Rosemary (Rosmarinus officinalis L.), sage (Salvia officinalis and turmeric (Curcuma longa) are among those with high antioxidant and antimicrobial activity (Hamed and AboElwafa, 2013; Özyurt, 2013; Ramadan and Wahdan, 2012; Ucak et al., 2011).

The objectives of this study were to prepare omega-3-rich flaxseed oil in water nanoemulsion using a high-pressure homogenizer instrument and to study the effect of using different molecular weight emulsifiers with different concentrations, different homogenization conditions and different continuous phase viscosity on the mean droplet size, polydispersity index (PDI) and zeta potential of the produced nanoemulsion. Also, the oxidative stability of the nanoemulsion supported by rosemary extract was investigated in order to obtain stabilized omega-3-rich oil in water nanoemulsion which could be incorporated into many functional food stuffs.

\section{MATERIALS AND METHODS}

\subsection{Materials}

Cold-pressed flaxseed oil and coconut oil were obtained as pure (crude) oils from the oil extraction unit at the National Research Centre (NRC), Dokki, Cairo, Egypt. Tween 20 (Polysorbate; Polyoxyethylene (20) sorbitan monolaurate) and sodium dodecyl sulfate (SDS) were purchased from Sigma Chemical Company. Pure soybean lecithin with 70\% phosphatidylcholine (Lipoid S 75) was purchased from Lipoid $\mathrm{GmbH}$, LudwigshafenGermany. Rosemary (Rosmarinus officinalis L.) leaves were purchased from a local herb store in Cairo, Egypt. All solvents and reagents were of the analytical grades needed for each application.

\subsection{Methods}

\subsubsection{Determination of fatty acid composition}

The methyl esters of fatty acids were prepared according to the standard method of AOAC (2005). Analysis of the prepared methyl esters was carried out according to Hamed et al., (2012). Such analysis was done usinf a gas chromatograph (Hewlett Packard HP 6890) with a capillary column $(30.0 \mathrm{~m}$ X $530 \mu \mathrm{m}, 1.0 \mu \mathrm{m}$ thickness, polyethylene glycol phase (INNO Wax) and flame ionization detector (FID). Nitrogen was the carrier gas at a flow rate of $15 \mathrm{ml} / \mathrm{min}$ and average velocity $89 \mathrm{~cm} / \mathrm{s}(8.2 \mathrm{psi})$. $\mathrm{H}_{2}$ flow rate was $30 \mathrm{ml} / \mathrm{min}$ and air flow rate was $300 \mathrm{ml} / \mathrm{min}$. A split/splitless controlled injector was used with a split ratio of $8: 1$, split flow of $120 \mathrm{ml} / \mathrm{min}$ and gas saver of $20 \mathrm{ml} / \mathrm{min}$. The injection, column and detector temperatures were 280, 240 and $280^{\circ} \mathrm{C}$, respectively. Elution of the fatty acid methyl esters was carried out according to a programmed 
temperature from $100{ }^{\circ} \mathrm{C}$ to reach a maximum of $240{ }^{\circ} \mathrm{C}$ at a rate of $10{ }^{\circ} \mathrm{C} / \mathrm{min}$ and held at $240{ }^{\circ} \mathrm{C}$ for $10 \mathrm{~min}$. Identification of the peaks was made by comparing with the chromatograms of standard fatty acid methyl esters (Sigma, USA).

\subsubsection{Ultrasonic-assisted extraction of rosemary leaves}

Extraction was carried out according to Hamed and Abo-Elwafa (2013). Briefly, three grams of dried ground rosemary leaves were ultrasonicated with $60 \mathrm{ml}$ of methanol for $20 \mathrm{~min}$ in an ultrasonic bath (Bandelin Sonorex, Germany, 480 W, 35 KHZ). The extract was then filtered through filter paper No. 1. Re-extraction was performed with two $20-\mathrm{ml}$ methanol portions. The combined filtrate was transferred to a $100 \mathrm{ml}$ measuring flask and filled with methanol to the mark.

\subsubsection{Preparation of nanoemulsions}

Flaxseed: coconut (1:1 wt/wt) oil/water emulsions were formulated through homogenization of $5 \mathrm{wt} \%$ lipid phase containing $60 \mathrm{mg}$ rosemary extract with an aqueous phase $(95 \%)$ consisting of $2,4,6$, or $8 \mathrm{wt} \%$ emulsifier (Tween 20, SDS, or soy lecithin), 0-50 wt $\%$ glycerol and filled with distilled water. The two phases were blended with the aid of a high speed mixer (Ingenieubüro CAT, M Zipperer Gmbh, Germany) at $16000 \mathrm{rpm}$ at room temperature for two minutes. The produced coarse emulsions were formulated into nanoemulsions after introduction to the high pressure homogenizer (HPH IKA®LABOR- PILOT, 2000/4, Germany). The coarse emulsion passed inside the homogenization chamber (1-8 cycles) under different pressures (500-1500 bar).

\subsubsection{Determination of viscosity}

The prepared nanoemulsions were tested for their viscosity using a Brookfield R/S Rheometer (Brookfield Engineering, Middleboro, MA) with a spindle number 1 in triplicate at $25 \pm 1{ }^{\circ} \mathrm{C}$ and $100 \mathrm{rpm}$.

\subsubsection{Nanoemulsion characterizations}

The formulated nanoemulsions were characterized through the assessment of the cumulant analysis produced using a dynamic light scattering (DSL) instrument. In DSL system characterization of the dispersion of molecules in solutions is followed up by measuring the mean particle size diameter (Z-Average), and a width parameter generally known as the polydispersity index (PDI), as well as the zeta potential ( $\xi$-potential, or droplet charge). A NICOMP 380 ZLS zetasizer dynamic light scattering instrument (PSS, Santa Barbara, CA, USA) was used for the determination of the above-mentioned characteristics. $632 \mathrm{~nm}$ line of a He Ne laser served as the incident light at an angel of $90^{\circ}$ and the external angel of Zeta potential was $18.9^{\circ}$. The samples were diluted 10 times in distilled water at ambient temperature. The hydrodynamic diameter $\left(H_{d}\right)$ was presented as the mean droplet diameter. The polydispersity Index (PDI) is a dimensionless parameter which measures the distribution intensity of each particle fraction and indicates the heterogeneity (monodisperse or polydisperse) of sizes of particles in a mixture. Each sample was analyzed in a disposable polystyrene cell (DTS0012, Malvern Instruments). The calculations used for the determination of size and PDI parameters are defined in the ISO standard documents 13321:1996 E and ISO 22412:2008 (Malvern Instruments Worldwide, 2011). The measurements were performed in duplicate, with three readings for each of them.

\subsubsection{Oxidative stability study}

Oxidation stability (OS) of the optimized nanoemulsion formulation ( $2 \%$ Tween 20 , homogenized at 1000 bar for 6 passes) was monitored over an eleven-week period of storage under room temperature condition $\left(25 \pm 1{ }^{\circ} \mathrm{C}\right)$. OS was followed up by measuring the peroxide value (PV) according to AOCS (2005).

\subsubsection{Statistical analysis}

Statistical analyses were done using one-way ANOVA and least significant differences between means were calculated. The Statistical Package for Social Sciences (SPSS) for Windows version (14.0) was used to analyze the data (SPSS Inc., Chicago, IL). Statistical significance was calculated at $\mathrm{p}<0.05$ (Snedecor and Cochran, 1994).

\section{RESULTS}

\subsection{Fatty acids analysis}

Table 1 shows the fatty acid compositions of flaxseed and coconut oils and their oil blend. Saturated fatty acids were found to be the major fatty acids in coconut oil $91 \%$, where lauric acid constituted $48 \%$, caprylic $8.5 \%$, capric $7.5 \%$, myristic $16 \%$ and palmitic acid $9 \%$. Unsaturated fatty acids constituted only $9 \%$ with $7 \%$ oleic acid and $2 \%$ linoleic acid. On the other hand, unsaturated fatty acids were predominant in flaxseed oil, where linolenic acid $(\omega-3)$ was the major fatty acid at $48.2 \%$, with oleic at $22 \%$, linoleic at $18.3 \%$ and palmitic acid $7.1 \%$. As a result of blending, large variations were noticed in the contents of lauric, oleic, linoleic and linolenic acids of the starting oils. Mixing flaxseed oil with coconut oil at a ratio of $1: 1 \mathrm{wt} / \mathrm{wt}$ caused a 
TABLE 1. Fatty acids analysis of coconut and flaxseed oils and their blend

\begin{tabular}{|c|c|c|c|}
\hline Fatty Acid & Coconut Oil & Flaxseed Oil & Blend (Flax-Coconut) \\
\hline Caprylic (C8:0) & $8.54 \pm 0.12^{\mathrm{a}}$ & ND & $3.94 \pm 0.14^{\mathrm{b}}$ \\
\hline Capric (C10:0) & $7.55 \pm 0.09^{\mathrm{c}}$ & ND & $3.18 \pm 0.03^{\mathrm{d}}$ \\
\hline Lauric (C12:0) & $48.17 \pm 0.14^{\mathrm{f}}$ & ND & $23.72 \pm 0.08^{\mathrm{e}}$ \\
\hline Myristic (C14:0) & $16.02 \pm 0.11^{\mathrm{ab}}$ & $0.74 \pm 0.05^{\mathrm{ac}}$ & $8.60 \pm 0.05^{\mathrm{de}}$ \\
\hline Palmitic (C16:0) & $9.03 \pm 0.15^{\mathrm{ac}}$ & $7.14 \pm 0.08^{\mathrm{cd}}$ & $6.71 \pm 0.09^{\mathrm{cd}}$ \\
\hline Stearic (C18:0) & $2.09 \pm 0.12^{\mathrm{de}}$ & $3.73 \pm 0.06^{\mathrm{ad}}$ & $4.62 \pm 0.08^{\mathrm{ae}}$ \\
\hline Oleic (C18:1) & $7.00 \pm 0.15^{\mathrm{cd}}$ & $22.04 \pm 0.08^{\mathrm{fg}}$ & $9.64 \pm 0.16^{\mathrm{hi}}$ \\
\hline Linoleic (C18:2) & $2.12 \pm 0.08^{\mathrm{fg}}$ & $18.3 \pm 0.10^{\mathrm{gh}}$ & $8.31 \pm 0.11^{\mathrm{jk}}$ \\
\hline Linolenic (C18:3) & ND & $48.16 \pm 0.09^{\mathrm{pq}}$ & $31.32 \pm 0.14^{\mathrm{rt}}$ \\
\hline${ }^{1} \mathrm{TSF}$ & $91.07 \pm 0.12^{\mathrm{abc}}$ & $11.52 \pm 0.08^{\mathrm{def}}$ & $50.73 \pm 0.05^{\mathrm{ghi}}$ \\
\hline${ }^{2}$ TUSF & $9.00 \pm 0.11^{\mathrm{pqy}}$ & $88.50 \pm 0.10^{\mathrm{klm}}$ & $49.27 \pm 0.16^{\mathrm{ghi}}$ \\
\hline${ }^{3} \mathrm{US} / \mathrm{S}$ & $0.098 \pm 0.006^{\mathrm{gfr}}$ & $7.68 \pm 0.02^{\mathrm{hfg}}$ & $0.97 \pm 0.02^{\mathrm{kml}}$ \\
\hline
\end{tabular}

${ }^{1}$ Total saturation, ${ }^{2}$ Total unsaturation, ${ }^{3}$ Unsaturation: saturation ratio

Data in the same row with different superscript letters are significantly different $(\mathrm{P}<0.05)$.

Each value represents mean $\pm \mathrm{SD}(\mathrm{n}=3)$

significant $(\mathrm{p}<0.05)$ increase in the total content of saturated acids (from $11.5 \%$ to $50.73 \%$ ) and a significant $(\mathrm{p}<0.05)$ reduction in the total content of unsaturated fatty acids (from $88.5 \%$ to $49.27 \%$ ) as observed in Table 1 . The results indicated that total saturated acids were increased by more than $440 \%$, whereas total unsaturated acids decreased by more than $55 \%$. Such significant changes in total saturated and unsaturated acids could enhance the oxidative stability of the formulated nanoemulsion (Hamed and Abo-Elwafa, 2013; Bhardwaj et al., 2015). Bhardwaj et al., (2015) concluded that blending flaxseed oil with oils rich in saturated fatty acids greatly enhanced its resistance against oxidation by decreasing the content in polyunsaturated fatty acids (which are more sensitive toward oxidation than saturated fatty acids).

\subsection{Effect of type and concentration of the emulsifier on droplet size}

Formulation, stability, as well as physicochemical characteristics depend on the emulsifier as a corner stone of the whole emulsion system. Food and nutrition sectors use different types of emulsifiers. Phospholipids, proteins, and polysaccharides are used extensively as emulsifiers for nutraceuticals and food industries (Benichou et al., 2004; McClements, 2015). Therefore, the effect of type and concentration of emulsifier on nanoemulsion formation using high-pressure homogenization is an important target in optimizing the proper methodology.

In our present work we examined the effect of three different types of emulsifiers on the droplet size: Zwitterion surfactant (Lecithin), a non-ionic surfactant (Tween20) and an anionic surfactant (sodium dodecyl sulfate, SDS). $5 \mathrm{wt} \%$ (flaxseed:coconut, 1:1 wt/wt) oil/water nanoemulsions with different emulsifier concentrations (2-8\%) of the above-mentioned emulsifiers (Lecithin, Tween 20, or SDS) were formulated with the highpressure homogenizer. Homogenization was carried out under high pressure (1000 bar) for 6 successive cycles. The droplet sizes were then measured.

The results (Table 2 and Figure 1) show the effect of emulsifier type and concentration on the droplet sizes. As shown, at $2 \%$ emulsifier concentration, the droplet sizes were 401.1, 179.9 and $110 \mathrm{~nm}$ for lecithin, Tween 20 and SDS, respectively. Variations in droplet size may be returned to variations in the molecular weight of the emulsifier used (Lecithin, $643.887 \mathrm{~g} / \mathrm{mol}$; Tween $20,522.676 \mathrm{~g} / \mathrm{mol}$ and SDS, $288.38 \mathrm{~g} / \mathrm{mol}$ ). Our results agreed with previous researchers (Karbstein and Schubert, 1995; Qian and McClements, 2011) who reported that by using fixed concentration and homogenization parameters, smaller molecular weight emulsifiers (e.g. SDS and Tween 20) showed superior efficiency to produce smaller droplets than larger molecular weight emulsifiers. Such efficiency may be due to the faster adsorbability of small molecules on the droplet surface.

Regarding the influence of emulsifier concentration, Table 2 shows that, for Tween 20, an increase emulsifier concentration from $2 \mathrm{wt} \%$ caused an insignificant decrease in the droplet diameter $(\mathrm{p}<0.05)$. As for SDS the lowest droplet size $(110 \mathrm{~nm})$ was produced at $2 \%$ concentration, while as the concentration increased a significant increase of more than $4 \%$ in droplet size occurred. On the other hand, lecithin-containing nanoemulsion showed a decreasing order of droplet size as the concentration of the emulsifier increased until the concentration reached $6 \%$ when a sudden and noticeable increase was registered thereafter (Table 2). 
TABLE 2. Impact of type and concentration of the emulsifier on the hydrodynamic diameter $\left(H_{d}\right)$ of the produced oil-in-water nanoemulsion (5 $\mathrm{wt} \%$ (flaxseed:coconut oils, 1:1 wt/wt) prepared at $1000 \mathrm{bar}$ and six passes).

\begin{tabular}{lcccc}
\hline & \multicolumn{4}{c}{ Hydrodymamic diameter $\left(\boldsymbol{H}_{d}, \mathbf{n m}\right)$} \\
\cline { 2 - 5 } Emulsifier Type & $\mathbf{2 \%}$ & $\mathbf{4} \%$ & $\mathbf{6} \%$ & $\mathbf{8} \%$ \\
\hline SDS & $110.1 \pm 4.13^{\mathrm{a}}$ & $112.9 \pm 5.41^{\mathrm{a}}$ & $184.3 \pm 5.16^{\mathrm{b}}$ & $232.2 \pm 6.93^{\mathrm{c}}$ \\
Tween 20 & $179.9 \pm 7.00^{\mathrm{d}}$ & $174.1 \pm 6.15^{\mathrm{d}}$ & $172.2 \pm 6.21^{\mathrm{d}}$ & $171.2 \pm 6.33^{\mathrm{d}}$ \\
Lecithin & $401.1 \pm 8.11^{\mathrm{e}}$ & $256.2 \pm 8.00^{\mathrm{f}}$ & $236.8 \pm 7.55^{\mathrm{g}}$ & $404.9 \pm 6.18^{\mathrm{e}}$ \\
\hline
\end{tabular}

Data in the same row with different superscript letters are significantly different $(\mathrm{P}<0.05)$. Each value represents mean $\pm \mathrm{SD}(\mathrm{n}=3)$

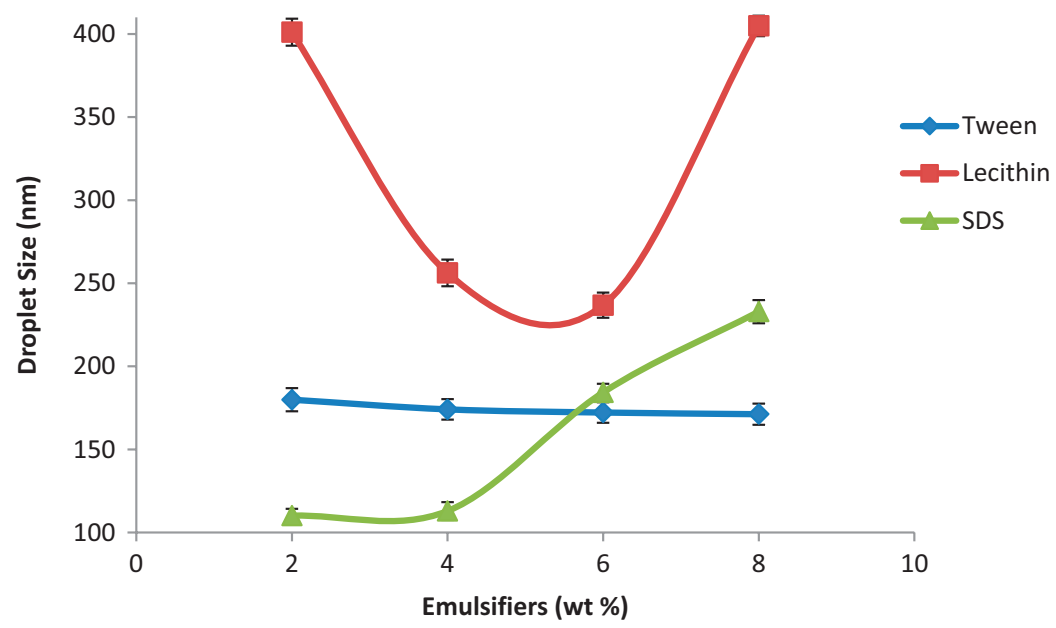

FIGURE 1. Impact of the emulsifier type and concentration on the average droplet diameter of the produced oil-in-water nanoemulsion ( $5 \mathrm{wt} \%$ (flaxseed:coconut, 1:1 wt/wt) prepared at 1000 bar and six passes) (Mean \pm standard deviation; Number of replicates for each analysis: 3; Statistical test: ANOVA and multiple comparison of means using SPSS; Degree of significance: $\mathrm{P}<0.05$ ).

Although it was theoretically expected that the droplet size would be decreased significantly for all the emulsifiers with increasing surfactant concentration so as to cover all oil droplets produced during homogenization, this did not actually happen, as shown in Table 2. This unexpected behavior may be interpreted either by proposing that not all emulsifier molecules are sufficiently adsorbed onto oil droplets or there was an insufficient disruptive force of the homogenizer at the operating pressure (Qian and McClements, 2011).

From a practical point of view, both SDS and lecithin were excluded for two reasons. First, although SDS showed the smallest droplet size $(110 \mathrm{~nm})$ it was excluded due to some health hazards for using it in the food sector (Anderson et al., 1986; Lindberg et al., 1991; Asonye et al., 2015). Second, if lecithin were used as the emulsifier it's concentration would have to be increased to reach a desirable droplet size which means more cost for producers who tend to use smaller emulsifier concentration due to regulatory and economic reasons. Therefore, using Tween 20 at $2 \%$ concentration satisfied the previous desired characteristics and at the same time was effective in generating nanoemulsions with acceptable droplet size (179-174 nm). Tween 20 was then used throughout the study.

\subsection{Impact of homogenization pressure and homogenization cycles on nanoemulsion characterizations}

Physicochemical properties and emulsion stability are greatly affected by emulsification parameters such as homogenization cycles and the pressure used inside the homogenization chamber (Yuan et al., 2008). Therefore, these parameters were investigated to assess their influence on the physicochemical properties of the $\omega-3$ based oil-inwater nanoemulsions.

Figure 2 illustrates that as the homogenization pressure or number of homogenization cycles increased the droplet went to a smaller diameter. There was a dramatic decrease in mean droplet diameter when the pre-emulsion passed the HPH at all tested pressures (Figure 2). Diameters decreased 


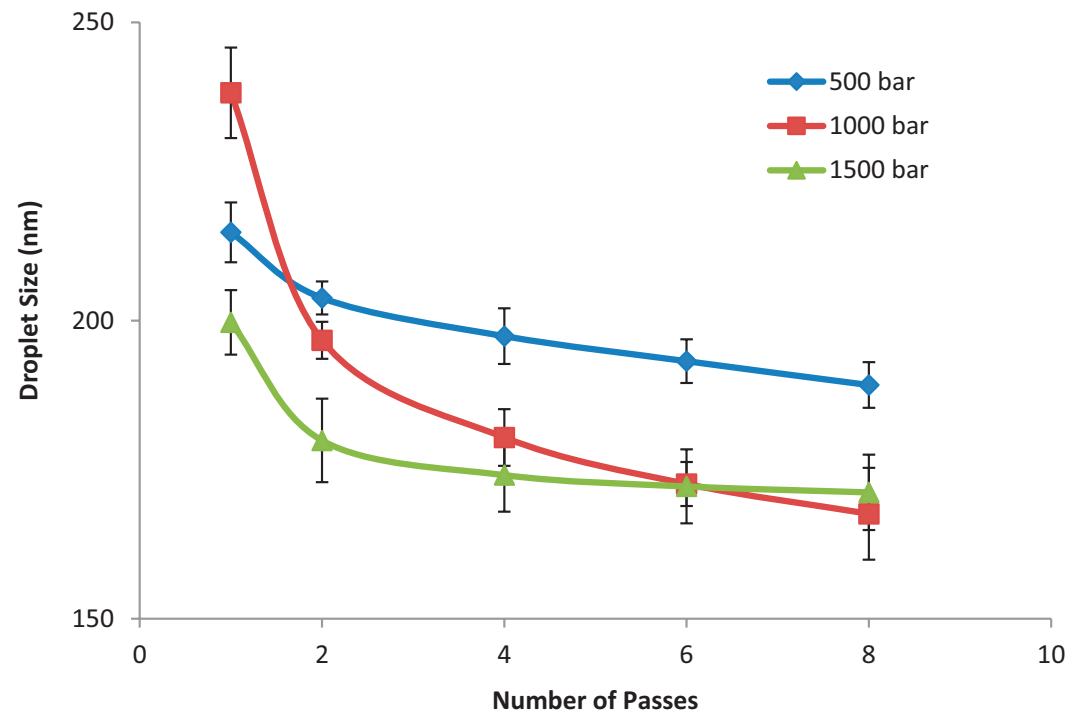

FIGURE 2. Impact of the homogenization pressure (in bar) and number of homogenization cycles (passes) on the average droplet diameter of the produced nanoemulsion (Mean \pm standard deviation; Number of replicates for each analysis: 3; Statistical test: ANOVA and multiple comparison of means using SPSS; Degree of significance: $\mathrm{P}<0.05$ ).

from $928.8 \mathrm{~nm}$ (Control Sample, data not shown on figure) to $214.8,238.2$, and $199.7 \mathrm{~nm}$ after one cycle at homogenization pressures of 500, 1000 and 1500 bar, respectively. This result is considered clear proof of the effective power of HPH to formulate nanoemulsions. Our results agreed with those previously reported (Qian and Mc Clements, 2011; Tan and Nakajima, 2005).

As for the effect of number of passes there was a pronounced decrease in droplet diameter with increasing passes from a single pass until the pass number six for all used pressures. Increasing homogenization more than six passes resulted in a moderate decrease in droplet diameter (Figure 2). As seen in Figure 2, there was no noticeable difference between the mean droplet diameter after six passes and emulsions prepared at 1000 bar and at 1500 bar. Also, Figure 2 shows that increasing the number of passes from six to eight at 1500 bar resulted in a very slight decrease in droplet diameter. Therefore, six homogenization cycles (passes) at 1000 bar was the method of choice to be proceeded with throughout the entire study.

The polydispersity index (PDI) is a dimensionless (see section 2.2.5) parameter and is represented in such a way that values smaller than 0.05 are rarely seen and values greater than 0.7 have a broad-size distribution and are not suitable to be analyzed by the dynamic light scattering technique (DLS). Algorithms with different size distributions work with those data that fall between these two extreme PDI values (i.e., 0.05-0.7). The calculations used for the determination of size and PDI parameters are defined in the ISO standard documents 13321:1996 E and ISO 22412:2008 (Malvern Instruments Worldwide, 2011).

The droplet size distribution of the prepared O/W nanoemulsion is shown in Figure 3 and Table 3. This distribution was uni-modal with accompanied polydispersity indices ranging from 0.123 to 0.334 . The results from the PDI show that all tested homogenizer pressures (500-1500 bar) and number of homogenization cycles ( 1 - 8 cycles) gave monomodal dispersions of the produced droplets.

The influence of the different processing conditions (homogenization pressure and homogenization cycles) on $Z p$ was also evaluated. The zeta potential is a stability indicator of colloidal dispersion systems. The magnitude of the zeta potential indicates the degree of electrostatic repulsion between adjacent, similarly charged particles in dispersion. So, for particles and molecules that are very small, the higher the magnitude of zeta potential the more stable is their colloidal system (i.e., the solution or dispersion will resist aggregation and flocculation). When $Z p$ is small, attractive forces will exceed this repulsion and the dispersion may break and flocculate. As presented in Table 3, $Z p$ values ranged from $-29.05 \mathrm{mV}$ to $-58.49 \mathrm{mV}$ for nanoemulsions produced with Tween 20 under the different homogenization conditions tested. A zeta potential of $\pm 30 \mathrm{mV}$ is believed to be sufficient for ensuring the physical stability of nanoemulsions (Gurpreetand Singh, 2018). Such high $Z p$ values obtained for the prepared nanoemulsions using Tween 20 as the emulsifier may be attributed to the composition of its backbone oil (free fatty acids and salts). McClements (2005) reported that even 


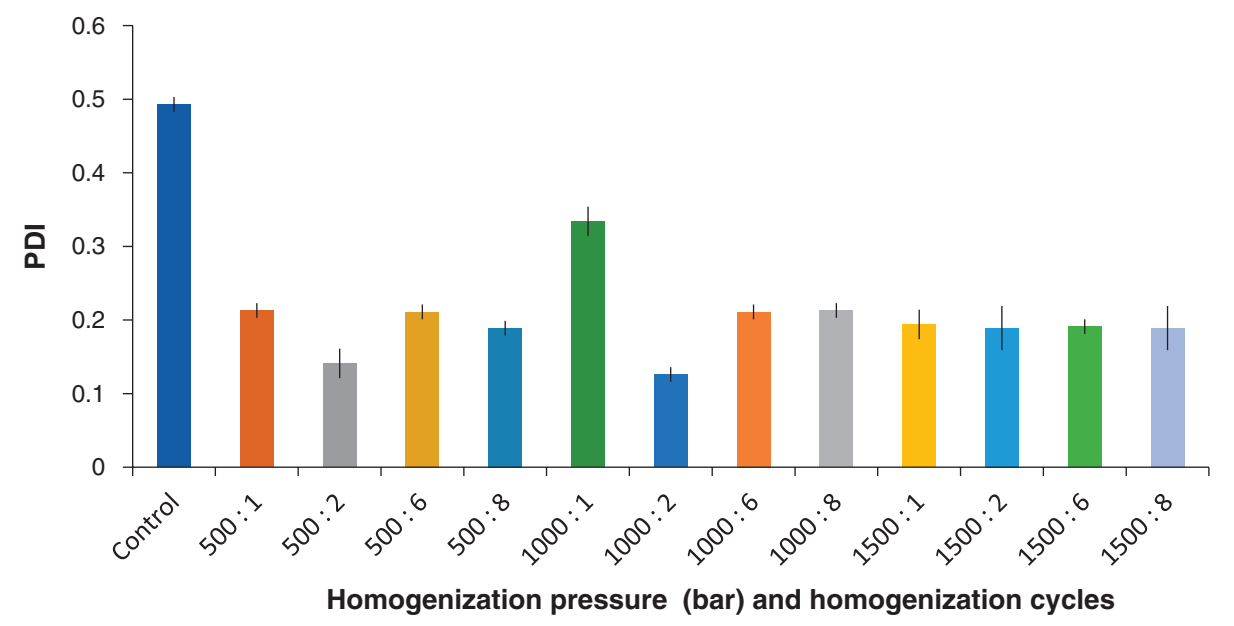

FIGURE 3. Impact of the homogenization pressure (in bar) and number of homogenization cycles (passes) on the polydispersity index (PDI) of the produced nanoemulsion. (Mean \pm standard deviation; Number of replicates for each analysis: 3; Statistical test: ANOVA and multiple comparison of means using SPSS; Degree of significance: $\mathrm{P}<0.05$ ).

TABLE 3. Impact of the homogenization pressure (in bar) and number of homogenization cycles on the polydispersity index (PDI) and zeta potential $(\mathrm{Zp})$ of the produced nanoemulsion

\begin{tabular}{lcl}
\hline Sample (pressure : cycles) & PDI & \multicolumn{1}{c}{$\boldsymbol{Z} \boldsymbol{p}(\mathbf{m V})$} \\
\hline Control & $0.493 \pm 0.01$ & $-8.38 \pm 1.1$ \\
$500: 1$ & $0.213 \pm 0.01$ & $-29.08 \pm 0.98$ \\
$500: 2$ & $0.141 \pm 0.02$ & $-29.18 \pm 2.1$ \\
$500: 6$ & $0.211 \pm 0.01$ & $-29.11 \pm 1.1$ \\
$500: 8$ & $0.189 \pm 0.01$ & $-29.05 \pm 2.3$ \\
$1000: 1$ & $0.334 \pm 0.02$ & $-31.05 \pm 1.8$ \\
$1000: 2$ & $0.126 \pm 0.01$ & $-32.33 \pm 1.1$ \\
$1000: 6$ & $0.211 \pm 0.01$ & $-34.55 \pm 0.99$ \\
$1000: 8$ & $0.213 \pm 0.01$ & $-58.49 \pm 4.5$ \\
$1500: 1$ & $0.194 \pm 0.02$ & $-38.81 \pm 2.62$ \\
$1500: 2$ & $0.189 \pm 0.03$ & $-37.27 \pm 1.88$ \\
$1500: 6$ & $0.191 \pm 0.01$ & $-33.44 \pm 3.11$ \\
$1500: 8$ & $0.189 \pm 0.03$ & $-30.79 \pm 1.87$ \\
\hline
\end{tabular}

Each value represents mean $\pm \mathrm{SD}(\mathrm{n}=3)$

at equilibrium, there was a continuous exchange of molecules between the interior of the droplets, the continuous phase and the interface.

\subsection{Effect of the viscosity of the continuous phase}

The influence of the continuous phase (aqueous phase) viscosity on both droplet diameter and PDI of the produced nanoemulsions was investigated at fixed conditions of homogenization (1000 bar, 6 passes) and 2\% Tween 20 as emulsifier. The oil phase was kept as is (flaxseed oil: coconut oil, 1:1wt/ $\mathrm{wt}$, at $5 \mathrm{wt} \%$ of total emulsion) but the aqueous phase was formulated to contain varying amounts of glycerol ( 0 to $50 \%$ of the aqueous phase) to change its viscosity before homogenization. As the glycerol content increased a parallel increase in the viscosity of the whole nanoemulsion was noticed (Table 4). As shown in Table 4, the nanoemulsion produced without glycerol (100\% water) showed the smallest droplet size $(172.6 \mathrm{~nm})$ as well as the narrowest range of size distribution $(\mathrm{PDI}=0.123)$. As the viscosity of the continuous phase increased by increasing glycerol concentration, fluctuation (irregular increase and decrease) in droplet size was observed (Table 4). The results of the present study disagreed with the results of Ramisetty and Shyamsunder (2011) who reported that droplet size increased by increasing the viscosity of the continuous phase. On the other hand, Qian and McClements (2011) revealed that using b-lactoglobulin as the emulsifier produced a slight change in droplet size while using small molecules (e.g. SDS) as surfactant caused a pronounced decrease in the size of the droplets with increasing aqueous-phase viscosity. Such variations in results may be due to differences in emulsifier type or homogenization equipment used.

\subsection{Oxidative stability of the prepared nanoemulsion}

During the oxidation of lipids there is a continuous formation of hydroperoxides (primary oxidation products) that in turn break down to a variety of nonvolatile and volatile secondary products. The formation rate of hydroperoxides exceeds their rate of decomposition during the initial stage of oxidation, and this becomes reversed at later stages (Shahidi and Zhong, 2005). Therefore, peroxide value $(\mathrm{PV})$ is a very important indicator of oxidative 
TABLE 4. Impact of continuous-phase viscosity on droplet size and polydispersity index (PDI) of the produced nanoemulsion

\begin{tabular}{lccc}
\hline Aqueous Phase Composition & Viscosity* $^{*}(\mathbf{P})$ & Droplet Size (nm) & PDI \\
\hline III $_{\text {0 G:100 W }}$ & $0.812 \pm 0.06$ & $172.6 \pm 3.17$ & $0.123 \pm 0.02$ \\
III $_{10}$ G:90 W & $1.144 \pm 0.01$ & $187.2 \pm 4.26$ & $0.214 \pm 0.006$ \\
III $_{20 \text { G:80 W }}$ & $1.238 \pm 0.003$ & $203.3 \pm 5.80$ & $0.197 \pm 0.008$ \\
III $_{30}$ G:70 W & $1.528 \pm 0.03$ & $200.7 \pm 4.7$ & $0.264 \pm 0.01$ \\
III $_{40}$ G:60 W & $1.566 \pm 0.03$ & $201.8 \pm 4.19$ & $0.232 \pm 0.011$ \\
III $_{\mathbf{5 0} \text { G:50 W }}$ & $1.969 \pm 0.03$ & $189.7 \pm 5.35$ & $0.260 \pm 0.01$ \\
\hline
\end{tabular}

Viscosity* in centipoise (cP) measured at $25^{\circ} \mathrm{C}$ and $100 \mathrm{RPM}$

Each value represents mean $\pm \mathrm{SD}(\mathrm{n}=3)$

stability. Also, it has been well established that primary oxidation products (e.g. hydroperoxide formation) increases with increasing unsaturation. For example, linoleic acid (C18:2) has been estimated to be 10 40 times more susceptible to oxidation than oleic $(\mathrm{C} 18: 1)$ and linolenic acids $(\mathrm{C} 18: 3, \mathrm{n}-3)$ and is far more readily oxidized than linoleic acid (Yun and Surh, 2012; McClements and Decker, 2008).

The oxidative stability of bulk oils is affected by its fatty acid composition. In our present work blending flaxseed oil with coconut oil $(1: 1, \mathrm{wt} / \mathrm{wt})$ was first carried out to tailor the fatty acid composition in such a way as to decrease the total polyunsaturated acids and increase total saturated acids. This was the first step to enhaninge oxidative stability (see section 3.1.). As a second step, rosemary extract $(60 \mathrm{mg})$ was added to give more protection against oxidation because of its highly potent phenolic antioxidants (Kayashima et al., 2012; Nieto et al., 2011; Nieto et al., 2018). Finally, the effect of the nanoemulsification technique on the oxidative stability of the substrate oil was evaluated. As shown in Figure 4 the levels of lipid hydroperoxides formed were periodically measured for the bulk oils and the nanoemulsion stored at $25 \pm 1{ }^{\circ} \mathrm{C}$ over the entire storage period of 11 weeks. The results indicated that during the first two weeks of storage there was a slow and comparable increase in the PV of both the bulk oil and the nanoemulsion. Beginning from the 3rd week the difference between bulk oil and the nanoemulsion PV became more pronounced and the bulk oil PV (62.4 meq $\mathrm{O}_{2} / \mathrm{Kg}$ oil) became about 3 times higher than that of the nanoemulsion $\left(22.6 \mathrm{meq} \mathrm{O}_{2} /\right.$ $\mathrm{Kg}$ oil) at the end of storage period. These results could be interpreted in light of the interfacial properties of the prepared emulsion. While for bulk oil the site of oxidation is usually done at interface between the air and the oil surface, the site of oxidation in the case of emulsion is the interface between the oil and water. So, the invasion of oxygen onto the unsaturated sites on the fatty acids in case of bulk oil is far easier than its invasion into those inside the emulsion. Also, enhancement in oxidation stability may be caused by the shielding effect of the

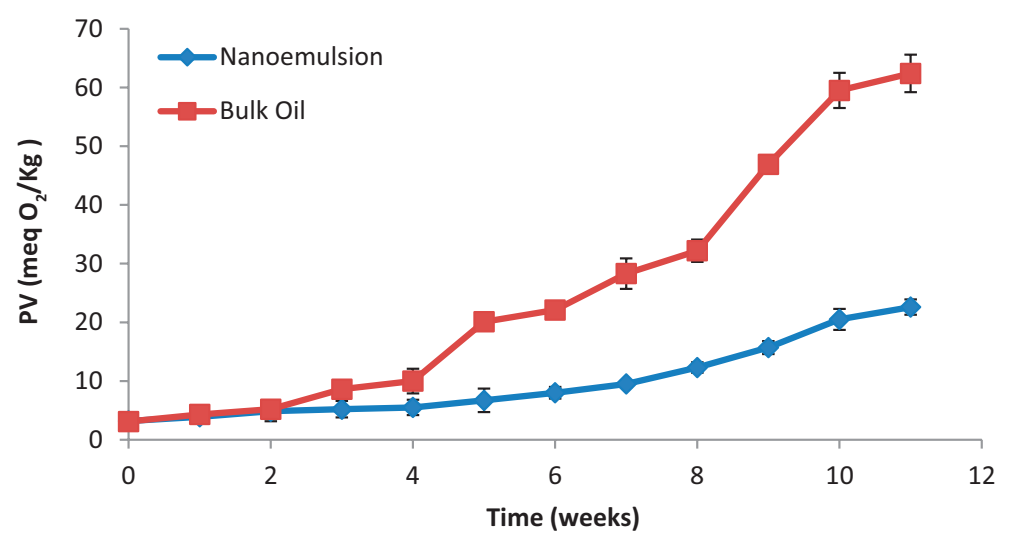

Figure 4. Peroxide value of the bulk oil and the produced nanoemulsion stored at $25 \pm 1{ }^{\circ} \mathrm{C}$ for 11 weeks (Mean \pm standard deviation; Number of replicates for each analysis: 3 ; Statistical test: ANOVA and multiple comparison of means using SPSS; Degree of significance: $\mathrm{P}<0.05$ ). 
emulsifier which formed interfacial barriers between the oil droplets and the invading oxygen.

\section{DISCUSSION}

Omega-3-rich oils (e.g. flaxseed oil), despite having great importance for many medications and food supplements, suffer rapid susceptibility to oxidation and may be improbably absorbed in bulk oil form. Therefore, our goal was to enhance their solubility and oxidative stability by formulating them into stable oil-in-water nanoemulsions.

The present work was carried out to study the influence of different parameters related to the emulsifiers used (concentration and type), homogenization process (homogenization pressure and number of passes inside the homogenizer), as well as the effect of continuous-phase viscosity on emulsion characteristics and stability.

The results demonstrated the effectiveness of using a pressure of 1000 bar and 6 passes through the high-pressure homogenizer in producing an $\mathrm{o} / \mathrm{w}$ nanoemulsion with the smallest droplet size as well as narrowest size distribution. Such characteristics are preferable for formulations required in both the pharmaceutical industries and the food sector.

Testing the effect of the emulsifier type and concentration revealed that although SDS (anionic surfactant) showed the smallest droplet diameter $(110 \mathrm{~nm})$ among all the emulsifiers used, there were some questionable marks about its use in food and oral pharmaceutical products. So, Tween 20 was the emulsifier of choice among the three tested emulsifiers as it satisfied both acceptable droplet size $(172.6 \mathrm{~nm})$ and narrow size polydispersity index $(0.123-0.334)$ required by many products like dairy and beverages.

Regarding continuous phase viscosity, it did not significantly affect the characteristics of the produced nanoemulsion.

Finally, the formulated o/w nanoemulsion was effectively stabilized against oxidation by using rosemary extract at a concentration of $60 \mathrm{mg} / 100 \mathrm{~mL}$ emulsion.

As a conclusion, omega-3 rich flaxseed oil can be preserved through the formulation of oil in water nanoemulsion, which exhibited higher oxidative stability than plain or bulk oils even in the presence of an antioxidant. Also, in terms of feasibility and health aspects using Tween 20 at concentration of $2 \%$ was adequate for preparing nanoemulsions with acceptable droplet size and size distribution at 1000 bar homogenization pressure and 6 cycles of homogenization.

The present work introduce a simplified way for producing a stable oil-in-water $(\mathrm{o} / \mathrm{w}) \omega-3$ fatty acid based nanoemulsion that could be incorporated into many pharmaceutical and food supplements.

\section{ACKNOWLEDGMENT}

The authors acknowledge the National Research Center of Egypt for providing the funds and facilities for this research project.

\section{REFERENCES}

American Oil Chemists' Society AOCS, 2005. Official Methods and Recommended Practices of the American Oil Chemists' Society, 5th edn. American Oil Chemists' Society, Champaign.

Anderson C, Sundberg K, Groth O. 1986. Animal model for assessment of skin irritancy. Contact Dermatitis 15, 143-51.

AOAC, 2005. Official Methods of Analysis of the Association of Official Analytical Chemists. AOAC International, Gaithersburg, USA.

Asonye CC, Livinus M, Akpalaba RU, Agu GC, Engwa AG. 2015. Effect of Sodium Lauryl Sulfate (SLS) on the External Adnexia of the Rabbit Eye. Res. J. of Pharm. Toxicol. 01, 12-14.

Benichou A, Aserin A, Garti N. 2004. Double emulsions stabilized with hybrids of natural polymers for entrapment and slow release of active matters. Adv. Colloid Interface 108-9, 29-41. https://doi.org/10.1016/j.cis.2003.10.013

Bhardwaj K, Verma N, Trivedi RK, Bhardwaj S, Shukla N. 2015. A novel approach for improvement of oxidative stability of flaxseed oil by blending with palm oil. Int. J. Adv. Res. 3, $1399-1407$.

Comporti M. 1993. Lipid peroxidation. Biopathological significance. Molecular Aspects Medic. 14, 199-207.

Din JN, Newby DE, Flapan AD. 2004. Omega 3 fatty acids and cardiovascular disease-fishing for a natural treatment. BMJ 328, 30-35. https://doi.org/10.1136/bmj.328.7430.30

Fortin PR, Lew RA, Liang MH, Wright EA, Beckett LA, Chalmers TC, Sperling RI. 1995. Validation of a metaanalysis: the effects of fish oil in rheumatoid arthritis. J. Clin. Epidemiol. 48, 1379-1390.

Guglielmini G. 2008. Nanostructured novel carrier for topical application. Clin. Dermatol. 26, 341-346. https://doi. org/10.1016/j.clindermatol.2008.05.004

Gurpreet K, Singh SK. 2018. Review of Nanoemulsion Formulation and Characterization Techniques. Indian J. Pharm Sci. 80 (5), 781-789. https://doi.org/10.4172/ pharmaceutical-sciences. 1000422

Hamed SF, Abo-Elwafa GA. 2013. Comparison between Four Different Techniques In Extraction Of Natural Antioxidants. J. Food Indus. Nutr. Sci. 3, 43-53.

Hamed SF, Wagdy SM, Megahed MG. 2012. Chemical Characteristics and Antioxidant Capacity of Egyptian and Chinese Sunflower Seeds: A Case Study. Life Sci. J. 9, 421-429.

Hibbeln JR, Davis JM, Steer C, Emmett P, Rogers I, Williams C, Golding J. 2007. Maternal seafood consumption in pregnancy and neurodevelopmental outcomes in childhood (ALSPAC study): an observational cohort study. Lancet 369, 578-585. https://doi.org/10.1016/S0140-6736(07)60277-3

Kabri TH, Arab-Tehrany E, Belhaj N, Linde M, 2011. Physicochemical characterization of nanoemulsions in cosmetic matrix enriched on omega-3. J. Nanobiotech. 9, 41. https:// doi.org/10.1186/1477-3155-9-41

Karbstein H, Schubert H. 1995. Developments in the continuous mechanical production of oil-in-water macroemulsions. Chem. Eng. Proc. 34, 205-211. https://doi. org/10.1016/0255-2701(94)04005-2

Kayashima T, Matsubara K. 2012. Antiangiogenic effect of carnosic acid and carnosol, neuroprotective compounds in rosemary leaves. Biosci. Biotechnol. Biochem. 76, 115-119. https://doi.org/10.1271/bbb. 110584

Kris-Etherton PM, Harris WS, Appel LJ, American Heart Association Nutrition Committee. 2003. Fish consumption, fish oil, omega-3 fatty acids, and cardiovascular disease. Circulation 107, 512. https://doi.org/10.1161/01. CIR.0000038493.65177.94 
Lauritzen L, Hansen HS, Jørgensen MH, Michaelsen KF. 2001. The essentiality of long chain n-3 fatty acids in relation to development and function of the brain and retina. Prog. Lipid Res. 40, 1-94.

Lindberg M, Farm G, Scheynius A. 1991. Differential effects of sodium lauryl sulphate and non-ionic acid on the expression of CD1a and ICAM-1 in human epidermis. Acta Derm. Venereol. 71, 384-8.

Malvern Instruments Worldwide 2011. Dynamic Light Scattering, Common Terms Defined; Inform White Paper; Malvern Instruments Limited: Malvern, UK, pp. 1-6.

Mao L, Xu D, Yang J, Yuan F, Gao Y, Zhao, J. 2009. Effects of small and large molecule emulsifiers on the characteristics of $\beta$-carotene nanoemulsions prepared by high pressure homogenization. Food Technol. Biotechnol. 47, 336-342.

McClements DJ. 2005. Food Emulsions: Principles, practice, and techniques $\left(2^{\text {nd }}\right.$ ed). CRC Press, Boca Raton, Florida.

McClements DJ. 2015. Food emulsions: Principles, practice, and techniques $\left(3^{\text {rd }}\right.$ ed.). In CRC series in contemporary food science Boca Raton: CRC Press.

McClements DJ, Decker EA. 2008. Lipids. In Food Chemistry. Damodaran S, Parkin KL, Fennema OR, eds. CRC Press, Boca Raton, FL, USA. p 155-216.

Mcclements DJ, Rao J. 2011. Food-Grade Nanoemulsions: Formulation, Fabrication, Properties, Performance, Biological Fate, and Potential Toxicity. Crit. Rev. Food Sci. Nutr. 51, 285-330. https://doi.org/10.1080/10408398.2011. 559558

Nieto G, Estrada M, Jordán MJ, Garrido MD, Bañon S. 2011. Effects in ewe diet of rosemary by-product on lipid oxidation and the eating of cooked lamb under retail display conditions. Food Chem. 124, 1423-1429. https://doi. org/10.1016/j.foodchem.2010.07.102

Nieto G, Ros G, Castillo J. 2018. Antioxidant and antimicrobial properties of rosemary (Rosmarinus officinalis L.): A Review. Medicines 5, 98. https://doi.org/10.3390/ medicines 5030098

Özyurt G. 2013. Effects of rosemary (Rosmarinus officinalis) extract addition on oxidative stability of fried sea bream (Sparus aurata) during chill storage $\left(4^{\circ} \mathrm{C}\right)$. J. Food Proc. Pres. 37, 1039-1042. https://doi. org/10.1111/j.1745-4549.2012.00796.x

Peet M, Stokes C. 2005. Omega-3 fatty acids in the treatment of psychiatric disorders. Drugs 65, 1051-1059. https://doi. org/10.2165/00003495-200565080-00002

Qian C, McClements DJ. 2011. Formation of nanoemulsions stabilized by model food-grade emulsifiers using high-pressure homogenization: Factors affecting droplet size. Food Hydrocolloids 25, 1000-1008.
Ramadan MF, Wahdan KMM. 2012. Blending of corn oil with black cumin (Nigella sativa) and coriander (Coriandrum sativum) seed oils: Impact on functionality, stability and radical scavenging activity. Food Chem. 132, 873-879. https://doi.org/10.1016/j.foodchem.2011.11.054

Ramisetty KA, Shyamsunder R. 2011. Effect of Ultrasonication on Stability of Oil in Water Emulsions. Inter. J. Drug Delivery 3, 133-142.

Sagalowicz L, Leser ME. 2010. Delivery systems for liquid food products. Current Opinion in Colloid and Interface Science 15, 61-72. https://doi.org/10.1016/j.cocis.2009.12.003

Shafiq S, Shakeel F, Talegaonkar S, Ali J, Baboota S, Ahuja A, Khar RK, Ali M. 2007. Formulation development and optimization using nanoemulsion technique: A technical note. Pharm. Sci. Tech. 8, E12-E17. https://doi.org/10.1208/ pt0802028

Shahidi F, Zhong Y.2005. Lipid oxidation: Measurement methods. In F. Shahidi (Ed.), Bailey's industrial oil and fat products (6th ed., Vol. 1, pp. 357-386). Hoboken, NJ: JohnWiley \& Sons, Inc. https://doi.org/10.1002/047167849X.bio050

Snedecor GW, Cochran WG. 1994. Statistical Methods (8th ed.). New Delhi: Oxford and IBH Pub.

Tan CP, Nakajima M. 2005. $\beta$-Carotene nanodispersions: preparation, characterization and stability evaluation. Food Chem. 92, 661-71. https://doi.org/10.1016/j. foodchem.2004.08.044

Ucak İ, Özogul Y, Durmus M. 2011. The effects of rosemary extract combination with vacuum packing on the quality changes of Atlantic mackerel fish burgers. Inter. J. Food Sci. Tech. 46, 1157-1163. https://doi. org/10.1111/j.1365-2621.2011.02610.x

Wang X, Jiang Y, Wang Y, Huang M, Ho CT, Huang Q. 2008. Enhancing anti-inflammation activity of curcumin through O/W nanoemulsions. Food Chem. 108, 419-424. https://doi.org/10.1016/j.foodchem.2007.10.086

Wang XY, Wang YW, Huang R. 2009. Enhancing stability and oral bioavailability of polyphenols using nanoemulsions. In: Micro/Nanoencapsulation of Active Food Ingredients. Q. R. Huang, P. Given and M. Qian (Editors). ACS Symposium Series 1007. Washington, DC. https://doi. org/10.1021/bk-2009-1007.ch013

Yuan Y, Gao Y, Zhao J, Mao L. 2008. Characterization and stability evaluation of $\beta$-carotene nanoemulsions prepared by high pressure homogenization under various emulsifying conditions. Food Res. Inter. 41, 61-68. https://doi. org/10.1016/j.foodres.2007.09.006

Yun J-M, Surh J. 2012. Fatty acid composition as a predictor for the oxidation stability of Korean vegetable oils with or without induced oxidative stress. Prev. Nutr. Food Sci. 17, 158-165. https://doi.org/10.3746/pnf.2012.17.2.158 